\title{
IPBES土地退化和恢复专题评估报告及其潜在影响
}

\author{
张博雅 潘玉雪 徐 靖 田 瑜*
}

(中国环境科学研究院生物多样性研究中心, 北京 100012)

摘要: 随着国际社会对生物多样性保护和人类福祉关注度的提升, 土地退化作为全球面临的重要问题逐渐成为国 际公约和进程关注的热点问题。生物多样性和生态系统服务政府间科学政策平台(Intergovernmental Science-Policy Platform on Biodiversity and Ecosystem Services, IPBES)将“土地退化和恢复”列入2014-2018年工作方案, 开展评 估。2018年3月, 该评估报告在IPBES第六次全体会议上获得通过。本文概述了评估报告的主要内容和结论, 探讨 了对其他国际进程的可能影响。评估报告在IPBES概念框架的基础上, 厘清了土地退化的概念与内涵, 全面梳理了 土地退化对人类生活质量的影响, 阐明了土地退化的现状和进程, 分析了直接和间接驱动因素与土地退化的作用, 揭示了土地退化与人类福祉的关系, 提出了土地退化和恢复的对策建议。该项评估将为各国决策者制定政策工具 提供最有效的技术支撑, 为相关国际进程谈判提供重要的科学参考。中国作为生物多样性大国, 应重视IPBES的评 估机制并积极参与, 加强促进生物多样性和生态系统服务领域的科学成果转化, 适时针对国内关键问题启动相关 评估, 促进我国生态文明建设和山水林田湖草系统治理, 实现美丽中国的建设目标。

关键词：土地退化和恢复; 生物多样性; 生态系统服务; 人类福祉; IPBES

\section{IPBES thematic assessment on land degradation and restoration and its potential impact}

Boya Zhang, Yuxue Pan, Jing Xu, Yu Tian*

Biodiversity Research Center, Chinese Academy of Environmental Sciences, Beijing 100012

\begin{abstract}
With increasing international concern for biodiversity and human well-being, land degradation has increasingly become the foci of international conventions and processes. In the 2014-2018 Work Program of Intergovernmental Science-Policy Platform on Biodiversity and Ecosystem Services (IPBES), "Land degradation and restoration" was included as one of the three major thematic assessment activities. The assessment report was completed by three hundred experts around the world in three years and adopted at the sixth plenary meeting of IPBES in March 2018. This article outlines the main contents and conclusions of the assessment, discusses possible impacts on other international processes, and proposes future work within our country. Based on the conceptual framework of IPBES, the assessment report comprehensively clarified the impact of land degradation on human life quality, the status and progress of land degradation, the role of direct and indirect drivers on land degradation, the relationship between land degradation and human well-being, and proposed suggestions for mitigating land degradation and promoting restoration. The assessment will provide policy makers in various countries with effective technical support for formulating policy tools and scientific references for negotiation of relevant international processes. As a country with rich biodiversity, China should accord importance to IPBES assessment mechanism and actively participate in strengthening the promotion of scientific achievements in the field of conserving biodiversity, initiate assessment on key domestic issues related to biodiversity and ecosystem services in a timely manner, to promote the construction of ecological civilization in our country, adopt a holistic approach to conserving our mountains, rivers, forests, farmlands, lakes, and grasslands, achieve the construction goal of beautiful China.
\end{abstract}

Key words: land degradation and restoration; biodiversity; ecosystem services; human well-being; IPBES 
土地作为地球上一切生物赖以生存的必要条 件之一, 其健康状况是保护生物多样性和维持生态 系统服务稳定输出的重要因素。土地退化是目前全 球(除南极洲外)各大洲均面临的重要问题, 是涉及 人类及其他生命形式福祉的核心要素之一(Stavi \& Lal, 2015)。土地退化往往会造成土地生产能力下 降、人口迁移、粮食安全威胁、生物多样性丧失和 生态系统被破坏(Eswaran et al, 2001)。因此, 了解土 地等自然资源的健康现状, 开展土地退化和恢复驱 动因素的分析研究, 确定陆地生态系统面临的威胁, 并运用模型方法预测其未来变化趋势, 对于全球生 物多样性保护、维持生态系统的活力及增强人类福 祉有着重要的意义(兰存子等, 2015; 田瑜等, 2016; Díaz et al, 2018)。

2013年12月, 在土耳其安塔利亚召开的生物多 样性和生态系统服务政府间科学政策平台(Intergovernmental Science-Policy Platform on Biodiversity and Ecosystem Services, IPBES)第二次全体会议将 “土地退化和恢复”作为优先启动的专题评估项目 (马克平, 2012; IPBES, 2013)。该评估是回应中国、 法国、意大利、挪威、《联合国防治荒漠化公约》 (UNCCD)、《生物多样性公约》(CBD)以及德国生物 多样性研究科学政策平台(NEFO)等成员国和利益 敒关方, 向IPBES提出的开展土地退化和恢复专题 评估建议。IPBES开展土地退化和恢复专题评估, 将为各国决策者制定政策提供参考准则和技术支 撑，同时促进和支持《联合国防治荒漠化公约》偻 物多样性公约》等相关国际议程之间的协同增效。 百余位核心作者历时3年完成了评估报告，于 2018 年3月IPBES第六次全体会议上最终审议并通过了 该评估报告, 发布了其决策者摘要。

本文将以IPBES概念框架及工作方案为基础, 系统阐述IPBES全球土地退化和恢复评估的由来、 主要内容及结论, 分析该评估目前存在的问题以及 评估结果对IPBES和其他相关进程的可能影响, 并 重点分析该评估对我国土地退化和恢复研究的影 响, 为我国未来工作提出有针对性的政策建议。

\section{评估报告的主要内容}

土地退化与恢复评估报告首先明确了评估范 围和相关概念的含义, 提出了避免、减少和扭转土 地退化的方法, 以及土地恢复对于自然惠益、人类
福祉和生活质量的重要意义; 探讨了土地退化和恢 复的概念、看法和不同的世界观。其次, 分析了土 地退化的成因和有利于恢复的驱动因素, 评估了土 地退化和恢复的现状和趋势, 以及生物多样性和生 态系统功能的响应变化; 探讨了土地退化和恢复对 人类福祉变化产生的影响, 对生态系统服务和功能 的改变, 以及对人类的福祉和良好生活质量的影 响。第三, 评估运用情景和模型对未来30年土地退 化和恢复进行了预测, 以提醒决策者关注全球变化 的未来影响。最后, 评估提出了以相关政策和决策 为基础的评估工具、技术和行动, 旨在减少土地退 化和促进恢复。评估报告分 8 个章节及一份凝练了 报告主要结论和政策建议的决策者摘要(IPBES, 2018)。

\section{1 土地退化的现状}

土地退化是指生物多样性和生态系统功能和 服务持续下降甚至丧失而导致的一种土地状况，并 且这种状况在短时间内无法完全自主恢复(Eswaran et al, 2001)。据IPBES估计, 人类活动导致的土地退 化威胁着全球约 32 亿人的福祉, 可能导致地球物种 再一次发生大量灭绝。土地退化影响下的全球生态 系统服务所带来的经济损失高达 10.6 万亿美元/年 (ELD, 2015), 约占2010年全球国内生产总值(GDP) 的 $10 \%$ 以上。目前地球表面没有受到人类活动的干 扰的区域不足1/4, 预计到2050年, 这一比例将下降 到不足 $10 \%$, 这些区域主要集中在不适合人类利用 或居住的沙漠、山区、苔原和极地地区。湿地退化 特别严重, 自1900年以来全球有54\%的湿地损失。

\section{2 土地退化对生物多样性和生态系统服务的影响}

土地退化对生物多样性和人类福祉的影响最 直接的表现为: 野生物种数量的减少所导致的生物 多样性衰退, 全球土壤有机碳的流失所导致的生态 系统功能受损, 以及土地生产力下降对于地方和区 域粮食安全造成的威胁。除此之外, 土地退化还会 通过引起气候变化、生物入侵或人口迁徙等对生态 系统和生物多样性产生间接影响。评估报告预测到 2050年时, 土地退化和气候变化这两个因素将会使 全球作物产量平均减少 $10 \%$, 某些区域甚至减产 $50 \%$ 。由于土地生产力下降, 特别是在干旱地区将 更容易引发社会冲突。土地退化和气候变化还可能 迫使全球发生大规模的人口迁移。全球城市化趋势 同样在改变人与环境的关系, 城市化进程虽然提高 
了人类对水和燃料等资源的利用效率, 但同时也带 来了土地退化等环境问题。

\section{3 土地退化的主要驱动因素}

评估报告中土地退化的驱动力主要可归纳为 两类: 一类是直接作用于自然环境并使其发生改变 的驱动因素, 主要包括过度放牧、农业迅速发展、 天然林退化、其他自然资源开采、外来种入侵、工 业发展、基础设施建设及城市化加剧等; 而另一类 则是通过作用于一个或多个直接因素来触发环境 状况的改变, 例如人口数量增多、密度增大以及气 候变化等因素。

评估报告指出, 农田、牧场迅速扩张和管理的 不可持续性, 是全球土地退化最直接的驱动因素之 一。发达国家的高消费方式以及发展中国家和新兴 经济体消费水平的提高, 也在一定程度上加剧了全 球土地退化的进程。土地退化是加速气候变化的因 素之一, 而同时气候变化可以增加土地退化的影响, 降低土地恢复方案的可行性。土地退化进程会因气 候变化的影响而加剧, 气候变化可能会引发土壤侵 蚀、极端天气事件发生频率增加、森林火灾风险增 大、外来物种入侵加剧, 同时还可能带来病虫害和 病原体分布的变化, 从而影响土地退化进程。

\section{4 土地恢复的对策建议}

评估报告指出, 现有的多边环境协定及全球进 程，包括《联合国防治荒漠化公约》、《联合国气 候变化框架公约》(UNFCCC)、 《生物多样性公约》 及“联合国可持续发展目标(SDGs)”等，提供了全球 范围内前所未有的巨大平台, 以便各国共同采取行 动遏止和扭转土地退化。目前, 全球许多地区采取 的土地退化预防措施, 以及针对已退化土地的生态 功能与生物多样性恢复措施已取得初步成效。政 府、决策机构及相关土地管理者需要掌握足够的信 息才能对土地进行长期有效的管理; 各国开展土地 恢复技术研究的关键信息来源和技术支持则需要 有效的监测手段、调查措施和充足的资金保障。同 时, 废止导致土地退化的不当奖励措施, 制定合理 的激励措施, 有助于推动土地可持续管理的实践进 程。政府、决策者机构、土地管理者、科研工作者, 特别是地方社区居民都参与到制订、实施和评价更 可持续的土地管理措施中来, 这将在维持生物多样 性和人类福祉中起到关键性的作用。

评估报告指出, 有多种市场和非市场机制可缓
解土地退化和促进土地恢复。其中生态系统服务付 费、农业补贴、环保项目招标和生物多样性补偿等 市场机制，可以有效地缓解土地退化和促进土地恢 复; 但此类政策的有效实施需要强化体制能力和加 强监管, 以保证恢复成效。此外, 个人或地方社区 依据国家法律在适当程度上享有安全的土地保有 权、财产权和土地使用权，是采取行动防止土地退 化和生物多样性丧失以及恢复已退化土地的重要 条件。评估报告还指出消费形态、人口增长、科技 和服务模式的重大变革, 可以有助于避免、减少和 扭转土地退化, 实现能源、水和生计安全, 同时缓 解和适应气候变化, 遏止生物多样性丧失。

\section{评估对其他全球多边环境进程的潜在影呅}

从全球的角度出发, 遏止和扭转土地退化是减 缓和阻止生物多样性丧失和生态系统恶化的基本 要求, 也是里约三公约(UNCCD、UNFCCC和CBD), 以及联合国可持续发展目标直接或间接提出的目 标(Cowie et al, 2011), 而土地退化和恢复评估提供 的改善和解决土地退化、荒漠化和已退化土地恢复 问题的各项措施必将为实现里约三公约的战略计 划以及制定后续目标提供科学依据。

在UNCCD的工作背景下, 由于IPBES土地退 化和恢复评估报告反映了全球土地退化状况，揭示 了全球土地退化的驱动力及其对生物多样性和人 类福祉的影响，从而为有效制定恢复政策措施提供 了重要的科学信息源, 将有助于政府、社会各界就 如何遏制和扭转土地退化做出更佳的知情决策, 从 而推动实现公约“至2030年实现土地退化零增长”的 目标。

IPBES土地退化和恢复评估阐明了土地退化和 气候变化的相互作用机制, 为推动实现UNFCCC框 架下 “全球气温升高幅度控制在 $2^{\circ} \mathrm{C}$ 的范围之内”的 目标, 促进在避免、减少和逆转土地退化的基础上 形成最具成本效益的温室气体减排计划提供了多 学科知识基础, 同时也为公约下一步进程提供了科 学指导。

IPBES土地退化和恢复评估报告确定了陆地生 态系统面临的威胁，并根据全球案例提供了一系列 旨在减少环境、社会和经济风险以及土地退化影响 的最佳解决方案，这无疑将有助于实现“生物多样 性爱知目标”。但根据目前IPBES土地退化和恢复专 
题评估报告的结果来看, 想要实现“生物多样性爱 知目标” 中 “到2020年恢复至少 15\%的退化生态系 统” 目标, 前景不容乐观。评估报告指出, 土地退化 和恢复是一种相对的概念, 需要参考具体状态来检 验和评估退化的程度和恢复的进展, 评估提出设立 土地退化参考基线，并以此为基础开展评估及模型 模拟预测, 其结果将对CBD等国际公约科学合理地 确立2020年后新目标框架起到重要的参考和推动 作用(孙新章, 2016)。

另外, IPBES土地退化和恢复评估与联合国可 持续发展目标高度相关。联合国可持续发展目标将 防治荒漠化和土地退化纳入第15.3项目标, 提出到 2030年实现土地退化零增长, 虽然有证据表明人类 在2030年前遏止和扭转土地退化的目标将难以实 现, 但报告提出了避免、减少和扭转土地退化的有 效措施, 对未来可持续发展目标进一步提出土地恢 复对策方案和相关政策建议有着重要指导作用, 对 实现SDGs有着重要的推进作用。

\section{3 评估对我国的影响及存在问题}

近年来，我国推进了一系列土地资源保护和退 化土地修复工作。作为“全球干旱地区土地退化评 估项目”六个示范国之一, 我国开展了一系列监测 和评估工作, 恢复案例得到了国际广泛好评(江泽 慧，2013)。2016年，国务院印发《土壤污染防治行 动计划》, 简称 “土十条”; 科技部开展脆弱地区土地 与生态恢复的专项行动; 2017年, 国务院提出开展 第三次全国土地资源调查, 全面查清当前全国土地 利用状况，掌握真实准确的土地基础数据，健全土 地调查、监测和统计制度; 党的十九大也提出了 “开 展国土绿化行动, 推进荒漠化、石漠化、水土流失 综合治理，强化湿地保护和恢复”。

尽管如此，我国目前土地退化现状仍不容乐观， 主要存在以下几个方面的问题: (1)相关政策法规不 完善, 缺乏国家统一的政策来协调各部门统一行动, 各类职权分属国土资源、农业、林业和水利等部门， 阻碍了土地退化的综合治理、协调监管和防治工作 成效; (2)土地退化治理的激励措施较为单一, 不仅 限制了对土地退化防治机理的科学研究, 同时对恢 复社区的居民补贴不足，影响恢复措施的实施效果; (3)我国不乏围绕土地退化的影响因素展开的研究, 但是缺乏对其进一步梳理、分类与总结, 没有形成
针对各退化类型和方式的驱动因素研究的理论成果; (4)公众参与度低, 国际交流与合作有待进一步加强; (5)资金支持方面也需要落实, 进一步拓宽渠道。

\section{对我国相关工作的建议}

基于上述问题，就目前我国土地退化防治和恢 复工作提出如下建议。

\section{1 重视IPBES和其他国际评估机制, 加强能力建 设与资金投入}

UNCCD、UNFCCC、CBD、《关于特别是作为 水禽栖息地的国际重要湿地公约》(《拉姆萨尔湿地 公约》)等国际协定都有制止和扭转土地退化的条款 和规定。除此之外, 必须呼吁和鼓励各国在国家和 地方层面做出更大的承诺和开展更有效的合作，来 利用和执行这些机制。因此，我国应更加重视 IPBES等全球和区域尺度的评估机制, 解析其概念 框架，掌握其工作模式，运用其评价方法，在全国 尺度及不同生态地理区域内开展土地退化现状评 估，查明各区域内土地退化的现状，评定区域退化 程度及其未来演变趋势, 确定其可能的影响及应对 策略，为进一步开展土地退化监测、土地恢复技术 研究及制定恢复政策提供基础数据支撑(Hotes \& Opgenoorth, 2014; 田瑜等, 2015)。在投入资金的同 时，应借鉴评估中提出的社区参与、政府与其他机 构合作等模式，建立完善市场化、多元化生态补偿 机制。

\section{2 制定土地恢复的战略规划，建立健全监管体系}

结合IPBES评估结果与国外的实践经验，针对 我国目前土地退化和恢复存在的重点问题，制订土 地退化防治长远战略规划，全面统筹规划，构建完 善、可持续的政策体系和多部门综合协调机制，开 展和实施土地退化防治和土壤保护行动, 共享数据 信息，进行土地可持续管理的政策改革。统一制订 和实施有效政策来促进监管和实施激励，形成联动 机制来遏止和扭转土地退化。在国务院机构改革的 方案实施以来, 组建了自然资源部、生态环境部, 统筹了职权，明确了监管职能，对未来我国土地退 化的综合治理、协调监管和防治工作将起到积极的 作用。在目前已有的土地管理法、水土保持法、防 沙治沙法等基础上，推进土地退化防治的相关标准 和技术规范研究，完善现有的相关土地保护法律体 系，让监管有据可依。制定政策授予和保护个人和 
集体土地所有权, 增强地方社区的职能, 认可传统 知识和地区习俗在可持续管理土地中的作用。

\section{3 深入开展致危因素分析, 着力加强土地退化 和污染防治研究}

整合科研资源，开展土地退化致危因素分析， 加强土地退化和污染防治研究。借鉴IPBES土地退 化评估报告, 着重开展土地退化对淡水和海洋生态 系统、人类健康和福祉以及传染病传播的影响研究; 开展气候变化, 社会、经济和政策进程与土地退化 之间的相互作用关系的研究; 为促进退化土地恢复 和生态系统功能恢复和保护, 提供有力的基础数据 和科技支撑。同时，借鉴国外已有的监测体系与我 国目前的监测技术相结合，扬长避短，运用地理信 息系统、遥感和信息网络、大数据等现代集成技术 手段，建立土地退化监测和预警系统，监测全国及 不同生态地理区域尺度上的土地退化类型、范围及 程度, 动态模拟土地退化的趋势并进行预报, 发挥 其预警作用。运用情景和模型工具, 开展不同政策 情景下土地变化对生物多样性和生态系统服务潜 在影响的变化趋势的预测和研究工作, 为遏制土地 退化和恢复政策的制定实施国家层面的大规模协 调行动计划。另外, 加大适用技术推广力度, 建立 健全技术体系, 完善科技成果转化机制, 推动治理 与修复产业发展。

\section{4 进一步扩大宣传, 加强国际交流与合作}

加大宣传力度, 鼓励公众参与土地退化防治的 科普活动, 提升公众对土地健康、生物多样性保护 和生态系统重要性的认知。同时, 积极参与IPBES 等国际进程，与欧美等国家建立相关领域的合作与 交流，借鉴其规范的评估程序和先进的方法，提高 我国在土地退化和恢复专题领域的研究能力。借助 CBD第十五次缔约方大会、UNCCD缔约方大会、 IPBES全体会议等国际会议的平台, 将我国荒漠 化、石漠化、水土流失防治的成功经验和治理模式 转化为国际话语权, 扩大我国在国际事务中的代表 性和发言权, 贡献中国智慧和力量; 继续发挥负责 任大国作用, 承担环境责任, 履行环境公约, 落实 一系列重要国际战略思想, 积极参与全球治理体系 改革和建设。另一方面，邀请“一带一路”沿线国家， 共同协商建立合作机制，加强信息共享交流与国际 合作，共同推动“一带一路”沿线土地退化治理，为 推动实现全球土地退化零增长目标作出贡献。

\section{参考文献}

Cowie AL, Penman TD, Gorissen L, Winslow MD, Lehmann J, Tyrrell TD, Twomlow S, Wilkes A, Lal R, Jones JW (2011) Towards sustainable land management in the drylands: Scientific connections in monitoring and assessing dryland degradation, climate change and biodiversity. Land Degradation \& Development, 22, 248-260.

Díaz S, Pascual U, Stenseke M, Martín-López B, Watson RT, Molnár Z, Hill R, Chan KMA, Baste IA, Brauman KA, Polasky S, Church A, Lonsdale M, Larigauderie A, Leadley PW, Oudenhoven APE, Plaat F, Schröter M, Lavorel S, Aumeeruddy-Thomas Y, Bukvareva E, Davies K, Demissew S,Erpul G,Failler P, Guerra CA, Hewitt CL, Keune H, Lindley S, Shirayama Y (2018) Assessing nature's contributions to people: Recognizing culture, and diverse sources of knowledge, can improve assessments. Science, 359, 270 272.

ELD Initiative (2015) The Value of Land: Prosperous Lands and Positive Rewards Through Sustainable Land Management. http://www.eld-initiative.org/fileadmin/pdf/ELD-main -report_en_10_web_72dpi.pdf (accessed on 2018-07-26)

Eswaran H, Lal R, Reich PF (2001) Land degradation: An overview. In: Responses to Land Degradation (eds Bridges EM, Hannam ID, Oldeman LR, Pening de Vries FWT, Scherr SJ, Sompatpanit S), pp. 20-35. Oxford Press, New Delhi, India.

Hotes S, Opgenoorth L (2014) Trust and control at the Science-Policy Interface in IPBES. BioScience, 64, 389-393.

Intergovernmental Science-Policy Platform on Biodiversity and Ecosystem Services (IPBES) (2013) Report of the Second Session of the Plenary of the Intergovernmental Science-Policy Platform on Biodiversity and Ecosystem Services, pp. 1-96. Antalya, Turkey. https://www.ipbes.net/system/tdf/downloads/IPBES_2_17_en_0.pdf?file=1\&type=no de\&id=14621 (accessed on 2018-03-28)

Intergovernmental Science-Policy Platform on Biodiversity and Ecosystem Services (IPBES) (2018) Summary for Policymakers of the Thematic Assessment of Land Degradation and Restoration of the Intergovernmental Science-Policy Platform on Biodiversity and Ecosystem Services. https://www.ipbes.net/system/tdf/downloads/ipbes-6-15-add. 5_spm_ldr_english.pdf?file=1\&type $=$ node $\& i d=23015 \quad$ (accessed on 2018-12-14)

Jiang ZH (2013) Research on comprehensive monitoring and evaluation index system of land degradation in China's arid areas. World Forestry Research, 26(6), 1-4. (in Chinese with English abstract) [江泽慧 (2013) 全球变化背景下土地退 化防治的挑战与创新发展. 世界林业研究, 26(6), 1-4.]

Lan CZ, Tian Y, Xu J, Li JS (2015) Conceptual framework and operational model of Intergovernmental Science-Policy Platform on Biodiversity and Ecosystem Services. Biodiversity Science, 23, 681-688. (in Chinese with English abstract) 
[兰存子, 田瑜, 徐靖, 李俊生 (2015) 生物多样性和生态 系统服务政府间科学-政策平台的概念框架和运作模式. 生物多样性, 23, 681-688.]

Ma KP (2012) Intergovernmental Science-Policy Platform on Biodiversity and Ecosystem Services (IPBES): An IPCC for biodiversity. Biodiversity Science, 20, 409-410. (in Chinese) [马克平 (2012) IPBES: 生物多样性领域的 IPCC. 生物多样性, 20, 409-410.]

Stavi I, Lal R (2015) Achieving zero net land degradation: Challenges and opportunities. Journal of Arid Environments, 112, 44-51.

Sun XZ (2016) China's strategy to participating in the 2030 Agenda for Sustainable Development. China Population, Resources and Environment, 26(1), 1-7. (in Chinese with English abstract) [孙新章 (2016) 中国参与2030年可持续 发展议程的战略思考. 中国人口.资源与环境, 26(1), 1-7.]

Tian Y, Lan CZ, Xu J, Li XS, Li JS (2016) Assessment of pollination and China's implementation strategies within the IPBES framework. Biodiversity Science, 24, 1084-1090. (in Chinese with English abstract) [田瑜, 兰存子, 徐靖, 李秀 山, 李俊生 (2016) IPBES框架下的全球传粉评估及我国 对策. 生物多样性, 24, 1084-1090.]
Tian Y, Li JS, Lan CZ, Li XS (2015) Interpretation of the work programme of Intergovernmental Science-Policy Platform on Biodiversity and Ecosystem Services for the period 2014-2018. Biodiversity Science, 23, 543-549. (in Chinese with English abstract) [田瑜, 李俊生, 兰存子, 李秀山 (2015) 生物多样性和生态系统服务政府间科学-政策平 台2014-2018年工作方案解析. 生物多样性, 23, 543-549.]

United Nations (2015) Transforming Our World: The 2030 Agenda for Sustainable Development. https://sustainablede velopment.un.org/post2015/transformingourworld/publica tion. (accessed on 2018-03-28)

Vitousek PM, Naylor R, Crews T, David MB, Drinkwater LE, Holland E, Johnes PJ, Katzenberger J, Martinelli LA, Matson PA (2009) Nutrient imbalances in agricultural development. Science, 324, 1519-1520.

Zhou XB, Zhang YM (2009) Review on the ecological effects of $\mathrm{N}$ deposition in arid and semi-arid areas. Acta Ecologica Sinica, 29, 3835-3845. (in Chinese with English abstract) [周晓兵, 张元明 (2009) 干旱半干旱区氮沉降生态效应 研究进展. 生态学报, 29, 3835-3845.]

(责任编委: 薛达元 责任编辑: 时意专) 